\title{
Orientação e evitação ao êxito em uma população do nordeste brasileiro
}

\author{
Jesús Francisco Laborin Álvarez. \\ José Angel Vera Noriega ${ }^{1}$ \\ Francisco José Batista de Albuquerque \\ Carlos Eduardo Pimentel \\ Alessandra Patrícia de Araújo Dantas
}

\begin{abstract}
Resumo
Utilizou-se a versão ajustada da escala mexicana de orientação e evitação ao êxito para obter sua validade de construto e as diferenças por sexo, idade, religião, preferência política, escolaridade e renda na população paraibana. Contou-se com uma amostra com 600 pessoas, distribuída igualmente por sexo e nas três faixas etárias: 14-22, 23-35 e 36-60 anos. A análise fatorial com rotação Oblimin apresentou três fatores para orientação ao êxito e dois para evitação ao êxito. As mulheres apresentaram médias mais altas em insegurança ao êxito e mais baixas para competitividade e trabalho. Por grupo de idade, observaram-se diferenças para os jovens com uma média maior nas dimensões de evitação ao êxito e competitividade. Em grau de estudo, o grupo que cursa a segunda fase de ensino fundamental obteve médias mais altas nos fatores competitividade e insegurança ao êxito. Para ter parceira(o) houve diferenças significativas.

Palavras-chave: Orientação e evitação ao êxito; Personalidade; Psicometria; Nordeste brasileiro.
\end{abstract}

\section{Orientation and avoidance achievement in a northeastern Brazilian population}

\begin{abstract}
An adjusted version of the Mexican scale of achievement and avoidance orientation was used in a population of Paraíba to obtain it's construct validity and also the differences related to gender, age, religion, political position, school age, and income. A sample of 600 people (equal number of male and female subjects) was used and divided into three groups according to their ages: 14-22, 23-35, 36-60 years old. The factor analysis with Oblimin rotation presented three components for achievement orientation and two other ones for avoidance achievement. Women presented higher scores for insecurity towards achievement and lower scores for competitiveness and work. As for the age group differences, youngsters presented higher scores for the avoidance achievement and competitiveness dimensions. Besides that, the subjects who attend the last grades of elementary school had higher scores for competitiveness and also for insecurity toward achievement. As far as single-married significant differences in scores could be found.

Keywords: Achievement orientation and failure avoidance; Personality; Psychometrics; Northeast of Brazil.
\end{abstract}

\section{Introdução}

Explicar como as pessoas em geral e grupos, em particular, como estudantes universitários e desportistas, entre outros, estabelecem atribuições e se dirigem ao êxito e evitam o fracasso é uma das tarefas que mais chama a atenção na investigação psicossocial e educativa. Nesta temática, os construtos de orientação ao êxito e evitação ao fracasso dirigem a discussão teórica e metodológica (Díaz, Andrade \& La Rosa, 1989; Espinosa, 1999; Espinosa \& Reyes-Lagunes, 1991; Hayashi \& Weiss, 1994).

$\mathrm{Na}$ medição desses construtos têm-se proposto diversas teorias e modelos, cujos objetivos concernem à explicação de sua dimensionalidade fatorial e à relação que guardam com alguns processos psicológicos e da personalidade (Atkinson \& Raynor, 1974; Cofer \& Appley,
1971; Díaz, Andrade \& La Rosa, 1989; Horner, 1969; McClelland, 1985).

$\mathrm{Na}$ psicologia da personalidade têm prevalecido duas estratégias para a medição desses construtos. A primeira, chamada projetiva, provém de McClelland, Atkinson, Clark e Lowell (1953). Baseando-se na Teoria Motivacional de Murray e nos conceitos da Teoria da Personalidade, esta estratégia gera um índice comportamental de alto e de baixo êxito, por meio de narrações inspiradas em uma série de desenhos tomados do Teste de Apercepção Temática (TAT) (McClelland, 1985). A segunda estratégia, nomeada psicométrica, com autores como Mehrabian (1969), Herrenkohl (1972) e Spence e Helmreich (1978), emprega escalas de autoreporte validadas por construto.

Dos resultados obtidos por McClelland e colaboradores (1953) e Atkinson e Birch (1978), podem-se

${ }^{1}$ Endereço para correspondência:

Centro de Investigación em Alimentación y Desarrollo A. C. - Coordinación Desarrollo Regional - Apartado postal 1.735

Km 6 - Hermosillo - Nogales - Ejido la Victoria - 83000 - Hermosillo, Sonora México - Tel.: 6622800485

E-mail: avera@,cascabel.ciad.mx 
assinalar algumas das características que descrevem as pessoas motivadas para o alto êxito como aquelas que se esforçam por alcançar metas claras e reais; aproveitam de uma melhor maneira suas potencialidades e se orientam somente para envolver-se em tarefas onde provam suas habilidades. Por outro lado, as pessoas com baixo êxito tendem a ser motivadas, principalmente, pelo desejo de evitar o fracasso; por isso, buscam tarefas simples, assegurando-se de que não fracassarão, ou tarefas tão difíceis para as quais o fracasso não tem implicações negativas, posto que praticamente todos fracassariam nelas.

Com os anos desenvolveram-se muitas medidas de auto-relato (self-report) para mensuração dos construtos em questão (Edwards, 1959; Grough, 1964, citados em Hermans, 1970), assim como revisões críticas (Clake, 1973; Hamilton, 1975; Wortubra \& Prince, 1975 citados em Shaw \& Constanzo, 1982), que assinalam como mais sensíveis as seguintes escalas: o Prestatic Motivation Test (Teste de Motivação Prestático - PMT) de Hermans (1970) e as escalas PRF de Jackson em 1974 (citado em Mankeliunas, 1987).

O PMT de Hermans está baseado na teoria da motivação ao êxito de Atkinson e contém perguntas acerca dos níveis de aspiração, da tomada de riscos, dos esforços para alcançar maiores níveis de vida e da persistência (Hermans, 1970).

Inicialmente, para medir a orientação ao êxito na população estudantil de classe média norte-americana, uma das escalas mais amplamente usadas foi a "Work and Family Orientation Questionarie", de Helmreich e Spence (1977, 1978, citados em Reeve, 1994), que consta de 32 itens em escala tipo Likert. Os autores rechaçaram a idéia de orientação ao êxito como um construto unitário e criaram uma escala para medir quatro dos seus componentes: orientação laboral (desejo de fazer o melhor que pode em tudo o que faça), domínio (a persistência de completar tarefas, especialmente as difíceis), competitividade e despreocupação pessoal (orientação autônoma).

Estudos efetuados na América do Norte e na América Latina nos anos 1970 por Madsen, em 1972 e Cohen, em 1979, mostraram que os hispânicos se orientam com uma menor motivação para o trabalho, ao passo que outros autores argumentam que os hispânicos apresentam uma orientação para o trabalho tão forte como a dos angloamericanos (ver Díaz-Guerrero, 1993).

No México, Andrade e Díaz-Loving (1985), partindo do instrumento desenvolvido por Helmreich e Spence para medir orientação ao êxito, empregam somente as três primeiras dimensões. A escala ficou conformada a 22 itens e seus índices de consistência interna foram: domínio $(0,78)$, competência $(0,79)$ e trabalho $(0,81)$. As três dimensões explicaram $36,71 \%$ da variância total da escala; ademais, obtiveram-se diferenças nas dimensões de trabalho e de domínio para escolaridade dos pais. As mulheres aposentadas tiveram médias mais altas do que os homens nas mesmas condições.

Recentemente, Laborín e Vera (2000) validaram as escalas de orientação ao êxito, de Díaz, Andrade e La Rosa (1989), temor ao êxito, de Espinosa, Pick de Weiss e Reyes (1988) e evitação ao êxito, de Espinosa e Reyes-Lagunes (1991), com a população do noroeste do deserto do México, encontrando três dimensões para orientação ao êxito (competitividade, domínio e trabalho) e três dimensões para evitação ao êxito (insegurança ao êxito, dependência da avaliação social e expectativas de fracasso). As mulheres e o grupo de 40-46 anos apresentaram médias mais altas nessas três dimensões de evitação ao êxito. Por outro lado, a amostra de empresários e profissionais apresentou as médias mais altas nas dimensões de orientação ao êxito. Finalmente, os dados permitiram afirmar a dimensionalidade dos construtos em pauta.

No Brasil, e no restante da América Latina, tem-se dado uma grande ênfase à construção e padronização de instrumentos próprios e, em geral, instrumentos de comparação (Salazar, 1997). Tal é o caso de Oliveira, em 1982, que realizou a validação da escala de bem sobre papéis sexuais, com população brasileira, e que foi atualizada posteriormente por Hutz e Koller em 1992 (citado em Açuña, Bruner \& Ávila, 1994); La Rosa (1986), que validou a escala de lócus de controle em estudantes universitários; Girardi e Díaz-Loving (1990), na construção de um inventário multidimensional de atribuição de controle; Dela Coleta (1990), que constituiu uma escala de atribuição de causalidade; Gouveia e Clemente (1998), que também validam várias medidas (por exemplo: responsabilidade social, valores humanos e individualismocoletivismo); e De Souza, Koller, Hutz e Forster (1995), que validaram a lista de adjetivos de depressão escolar.

Em estudo recente, Noriega, Albuquerque, Laborín, Silva e Ávila, (2002) validaram uma escala para medir o autoconceito em uma amostra do nordeste brasileiro. Nessa pesquisa, os autores avaliam o autoconceito dos habitantes da Paraíba, observando que se descrevem como compreensivos, bons, carinhosos, amorosos, hospitaleiros, fraternais e demais condutas do tipo social. Em outras palavras, possuem um autoconceito eminentemente afiliativo, enfatizando um caráter jovial, tranquiilo, divertido e agradável, que trata de uma classe média que se define segundo a expressão de sua conduta social.

Dessa forma, o presente trabalho visa, essencialmente, a validação e confiabilidade da medida de orientação e evitação ao êxito e, por sua vez, levar a cabo uma análise comparativa das variáveis sociais dos 
indivíduos. Portanto, objetivou-se apresentar os resultados do estudo em duas partes. $\mathrm{Na}$ parte 1 adotou-se como objetivo a validação de construto das escalas de orientação ao êxito e de evitação ao êxito (Laborín \& Vera, 2000) com habitantes da cidade de João Pessoa, estado da Paraíba, no nordeste brasileiro. A parte 2, por sua vez, tem por finalidade efetuar comparações com as dimensões que constituem essas escalas e as diferenças sociais nos habitantes da região nordestina do Brasil.

A comparação por sexo tem sido considerada tradicionalmente na maioria dos trabalhos sobre algum traço de personalidade. Já que tal variável dá conta dos papéis e práticas de educação distintas para homens e mulheres (Bejar, 1983). Tal é o caso da descrição que se faz da mulher, a que se atribuem características afiliativas, enquanto que a dos homens é marcada pela atribuição de traços instrumentais. (Díaz-Guerrero, 1982)

Uma variável também escolhida para a comparação social foi a idade, pois representa a acumulação de experiência, aprendizagem, maturidade e o conhecimento que integra a pessoa em um dado momento da sua vida (Espinosa, 1999).

Os grupos de idade foram selecionados em razão da estreita relação entre as mudanças ocasionados pelo desenvolvimento e a idade cronológica (Kimmel, 1990, citado em Anguas, 1997), já que o nível de idade é considerado como um indicador das etapas relevantes da vida do indivíduo, tais como a transição da adolescência para o início da fase adulta, entrada definitiva no mundo adulto, da transição para a faixa dos 30 anos, o estabelecimento da identidade e a crise da metade da vida.

Reyes-Lagunes (1996) argumenta que o estudo de um intervalo de idade de 14-46 anos oferece vantagens para observar, com maior precisão, como os construtos de orientação ao êxito e evitação ao êxito, ou qualquer outro, vai se conformando ao longo da vida. Com respeito a isso, defende-se que nos jovens de 14 a 22 anos os construtos se apresentariam de forma não-diferenciada; a partir dos 23 anos se apresentariam em formação e, finalmente, nas pessoas de mais de 35 anos se encontrariam consolidados e diferenciados. $\mathrm{O}$ estudo anterior se baseia na suposição de que as pessoas, ao longo do desenvolvimento da personalidade, vão conformando seus distintos traços e que a consolidação de alguns serve de base para o desenvolvimento de outros (Michel, 1977; Hampson, 1986).

A importância de comparar grupos por escolaridade, outra variável que entra na comparação social dos grupos, se justifica por considerar a influência que exerce a educação formal no comportamento e integração da informação (Raynor, 1970). Por último, pretende-se comparar também a atividade de ocupação da pessoa, pois a atividade laboral representa diferentes desafios, assim como nível de preparação e expectativas de realização (Díaz-Guerrero \& Szalay, 1993), para pessoas com e sem parceira(o) (Anguas \& Reyes, 1998).

\section{Método}

\section{Participantes}

Contou-se com uma amostra de 603 pessoas do estado da Paraíba na região do nordeste brasileiro, as quais foram selecionadas de forma não-probabilística, pela técnica de amostragem por quotas. Essas quotas foram definidas em razão da idade, sexo e identidade cultural. Os três grupos de idade foram: adolescentes jovens (14-22 anos), jovens adultos (23-35 anos) e adultos (36-60 anos). A distribuição da amostra foi eqüitativa para faixa etária e sexo. Para participar do estudo, era necessário que a pessoa tivesse tempo de residência na Paraíba de, pelo menos, a metade de sua idade mais 5 anos, controlando-se assim a identidade cultural do participante.

Os participantes tinham as seguintes características sociodemográficas: $33,3 \%$ correspondiam ao grupo de adolescentes jovens; $32,5 \%$, ao grupo de jovens adultos, e $34,2 \%$, ao grupo de adultos. A média de idade entre os grupos era de 29 anos. Com relação às demais características, 66,3\% reportaram ser solteiros; 60\% provinham da zona urbana; $52,9 \%$ responderam que contribuíam com a renda sempre; $29,5 \%$ ganhavam entre 5 e 10 salários; 84,4\% mencionaram ter residência própria; $39,2 \%$ possuíam uma preferência política pelo Partido dos Trabalhadores (PT); 77\% referiram ser católicos; 45,3\% mencionaram possuir um grau de ensino médio; e 26,7\% afirmaram trabalhar em empresas públicas.

\section{Instrumento}

Utilizou-se a medida de orientação e evitação ao êxito elaborada para a população do noroeste do México (Laborín \& Vera, 2000), a qual ficou conformada a um total de 74 itens e um alfa de Cronbach de $0,90$.

Cada item é uma afirmação no presente, na primeira pessoa do singular e a resposta implica a eleição de uma de sete opções apresentadas no formato tipo Likert pictórico, com sete quadros equiláteros ordenados do maior para o menor tamanho, variando de $1=$ completamente de acordo até $7=$ completamente em desacordo (Reyes-Lagunes, 1993).

\section{Procedimento}

Para grupos de 14-22 anos e 23-35 anos, a aplicação do instrumento realizou-se com pessoas de diferentes níveis educativos (ensino médio e superior), indiscriminadamente, em situação coletiva de sala de aula. 
Para o grupo de 35-60 anos, a aplicação foi efetuada de maneira individual, nos lugares de trabalho, oficinas, casas e espaços livres, em virtude da dificuldade de encontrar tais sujeitos em um só cenário. Em todos os casos, as instruções foram lidas e explicadas em voz alta.

Os passos que se seguiram ao longo do estudo foram: a) tradução e retradução do instrumento para o português-espanhol, com o objetivo de assegurar que a linguagem utilizada, as instruções e o formato fossem claros e adequados à população; b) aplicação piloto da escala; c) aplicação da versão final aos grupos selecionados, segundo as variáveis-critério, tanto de forma individual como de forma coletiva; e d) tarefas de codificação e digitação.

\section{Seqüência das análises estatísticas}

Foram realizados os procedimentos estatísticos usuais e sugeridos para a validação por construto (Nunnally \& Bernstein, 1995). Primeiramente foram utilizados: o Teste t para grupos independentes, item por item, comparando grupo alto $v$ s. grupo baixo (percentil 25 e 75, respectivamente); o alfa de Cronbach, com o propósito de obter o índice de confiabilidade total da prova; uma análise fatorial exploratória (Comrey, 1988) para se conhecer a estrutura do construto de orientação e evitação ao êxito.

Empregamos uma análise fatorial dos componentes principais, dado que esta leva em conta a soma dos valores observados para otimizar o peso de máxima variabilidade e confrabilidade dos fatores resultantes (Floyd \& Widaman, 1995). Adicionalmente, foram verificados os índices KMO e o Teste de Esfericidade de Bartlett, os quais indicam que os itens do instrumento são apropriados para a análise fatorial (ver Tabela 1); foi utilizada rotação oblíqua (Oblimin), porque era esperado que algumas dimensões da escala estivessem correlacionadas.

O número de fatores obtidos foi avaliado usando: a) a regra de Kaiser, Hunka e Bianchinf (1969) de extração dos fatores com valores próprios (eigenvalue) maiores que 1 , b) o indicador scree plot (Cattell, 1966) e c) a interpretabilidade das estruturas fatoriais resultantes (Gorsuch, 1983). Por fim, foram utilizados: o alfa de Cronbach por fator, para obter a confiabilidade por fator; e a análise de variância (ANOVA).

\section{Resultados}

Primeira parte: validação de construto das escalas e orientação ao êxito e de evitação ao êxito

Uma vez caracterizada a amostra, realizou-se um Teste $t$ para amostras independentes, para identificar o valor discriminativo dos itens. O total dos itens se mostrou significativo, a um $p<0,05$. Em seguida, levouse a cabo a análise fatorial (PAF), com rotação Oblimin, emergindo dois grandes fatores, aspecto que ratifica a conformação bifatorial do construto, em razão do que considerou-se a decisão de efetuar as análises em separado para cada dimensão (Laborín \& Vera, 2000).

A análise da escala de orientação ao êxito revelou nove fatores, com valores eigen maiores do que 1 , que em conjunto explicam $55,4 \%$ da variância total da escala. No entanto, por sua clareza conceitual, somente se tomaram os três primeiros fatores, com um total de 37 itens, que explicam 35,86\% e um índice de consistência interna de 0,88 (Tabela 1).

O primeiro fator, competitividade, apresentou um total de 22 itens, com uma variância explicada de 20,89\% e um alfa de Cronbach de 0,90, assim como médias maiores nos itens que avaliam aspectos relacionados com sentimentos e ações que representam o "vencer os outros". Algumas médias maiores do que 4 indicam que a população se orienta para condutas relacionadas com a competitividade.

$\mathrm{O}$ segundo fator, dominância, mostrou dez itens com 9,57\% de variância explicada, índice de consistência interna de 0,76 e médias altas nos itens que identificam características pessoais, como ser perfeccionista em várias atividades.

O terceiro fator, trabalho, apareceu com cinco itens, explicando $5,40 \%$ da variância, um alfa de 0,53 e médias maiores nos itens que avaliam aspectos instrumentais do sujeito em lograr que o trabalho dos demais seja avaliado negativamente em comparação com o seu. Pelas médias maiores que cinco se pode entender que os paraibanos percebem o trabalho em relação à competência e diferenciação hierárquica.

Com relação à análise da escala de evitação ao êxito, esta resultou conformada por um total de 28 itens, distribuídos em sete fatores, com valores eigen maiores do que 1, que em conjunto explicam 52,6\% da variância total. Entretanto, por sua claridade conceitual e carga fatorial, somente se selecionaram os primeiros dois fatores, explicando $35,19 \%$ da variância total e com um valor de alfa de 0,92 (Tabela 1).

O primeiro fator, insegurança ante a execução de tarefas, apareceu com 14 itens, explicando 30,00\% de variância e com um alfa de 0,88 , com médias altas nos itens que identificam respostas de insegurança antes e depois da tarefa.

O segundo fator, preocupação ante a avaliação social, com 14 itens, mostrou cargas fatoriais maiores do que 0,30 , uma variância explicada de 5,19\% e com um alfa de 0,85 , com médias altas nos itens que se referem a sentimentos de insegurança ante a avaliação dos demais.

Psico-USF, v. 11, n. 2, p. 207-217, jul./ dez. 2006 
Tabela 1 - Valores de média, variância explicada e consistência interna para as escalas de orientação e evitação ao êxito

\begin{tabular}{|c|c|c|c|c|}
\hline Subescalas & Médias & $\begin{array}{c}\% \text { de } \\
\text { variância } \\
\text { explicada }\end{array}$ & $\begin{array}{c}\text { Total da extração } \\
\text { da soma } \\
\text { dos quadrados }\end{array}$ & $\begin{array}{l}\text { Alfa de } \\
\text { Cronbach }\end{array}$ \\
\hline \multicolumn{5}{|l|}{ Orientação ao êxito } \\
\hline Competitividade & 3,61 & 20,89 & 7,72 & 0,90 \\
\hline Dominância & 5,81 & 9,57 & 3,14 & 0,76 \\
\hline Trabalho & 3,73 & 5,40 & 1,51 & 0,53 \\
\hline \multicolumn{5}{|l|}{ Total de variância } \\
\hline \multicolumn{5}{|l|}{ Alfa total: 0,88} \\
\hline \multicolumn{5}{|l|}{$\mathrm{KMO}=, 87 \mathrm{e}$} \\
\hline \multicolumn{5}{|l|}{ Teste de Esfericidade de Bartlett: } \\
\hline \multirow{2}{*}{\multicolumn{5}{|c|}{$\begin{array}{l}\text { Valor aproximado qui-quadrado: } \\
6245,36\end{array}$}} \\
\hline & & & & \\
\hline \multicolumn{5}{|l|}{$p<0,000$} \\
\hline \multicolumn{5}{|l|}{ Evitação ao êxito } \\
\hline Insegurança ante a execução & 3,99 & 30,00 & 9,57 & 0,88 \\
\hline Preocupação ante a avaliação & 4,18 & 5,19 & 1,15 & 0,85 \\
\hline social & & & & \\
\hline \multicolumn{5}{|l|}{ Total de variância explicada: } \\
\hline \multicolumn{5}{|l|}{$35,19 \%$} \\
\hline \multicolumn{5}{|l|}{ Alfa total: 0,92} \\
\hline \multicolumn{5}{|l|}{ KMO e Teste de Esfericidade de } \\
\hline \multicolumn{5}{|l|}{ Bartlett: 0,93} \\
\hline Valor aprox. qui-quadrado: 5172.11 & & & & \\
\hline$p<0,000$ & & & & \\
\hline
\end{tabular}

Método: fatorização dos eixos principais.

$\mathrm{Na}$ medida em que se verificam médias totais superiores a três, pode-se interpretar que os paraibanos, regularmente, se mostram inseguros e preocupados com a execução e o desempenho ante os demais.

\section{Análises de correlação entre as dimensões do construto}

Ao se correlacionarem as dimensões de orientação e evitação ao êxito, pode-se observar que a subescala de competitividade se correlaciona de maneira positiva com as demais dimensões, com valores baixos e moderados. Isso pode significar que o medo da avaliação e a resposta aos padrões de qualidade do trabalho estão relacionados com o exercício comparativo de superioridade entre os pares. Um modelo triangular de motivação ao êxito parece estar operando, com os vértices: competitividade, trabalho e evitação diante da avaliação social (ver Tabela 2).

Tabela 2 - Correlações de Pearson entre as dimensões de orientação e evitação ao êxito para o total da população

\begin{tabular}{lcccc}
\hline \multicolumn{1}{c}{ Dimensão } & Competitividade & Dominância & Trabalho & $\begin{array}{c}\text { Insegurança ante } \\
\text { a execução }\end{array}$ \\
\hline Competitividade & $0,10^{* *}$ & & & \\
Dominância & $0,49^{* *}$ & $-0,08^{*}$ & & \\
Trabalho & $0,28^{* *}$ & $-0,07$ & $0,37 * *$ & \\
Insegurança ante a execução & $0,45^{* *}$ & $-0,03$ & $0,48^{* *}$ & $0,70^{* *}$ \\
Preocupação ante a avaliação social & &
\end{tabular}
$* p<0,05 ; * * p<0.01$ 
A dimensão dominância se correlacionou de forma negativa com as demais dimensões. Isso supõe que os níveis de domínio e qualidade na execução do trabalho não estão relacionados, nessa população, com seu nível de aspirações.

Para a dimensão de insegurança ante a execução de tarefas, observa-se uma associação alta, com preocupação perante a avaliação, sugerindo que a subescala de evitação ao êxito é muito consistente.

\section{Segunda parte: comparações por variáveis sociais}

Para simplificar a explicação dos resultados, é importante considerar que num contínuo de 1 a 7 , em princípio existe um zero convencional e a gama de números possíveis se encontra entre um e sete. Portanto, o número 4 representa o ponto central de 1 a 7, o qual se define, convencionalmente, como o ponto zero. Do valor 4 ao 7 se encontram as freqüências e intensidades altas, pois esta escala mede um traço positivo de orientação ao êxito, de modo que, ainda quando temos itens negativos, todos os itens são avaliados no pólo positivo. O intervalo entre 6 e 7 indica uma percepção de freqüência muito alta, o de 5 a 6 implica uma freqüência alta e o de 4 a 5 significa certa regularidade. $\mathrm{O}$ intervalo de 3 a 4 representa uma baixa freqüência, que é o que se esperaria de itens negativos, enquanto de 2 a 3 a freqüência percebida é muito baixa. Assim, ao se verificarem itens que descrevem características negativas do comportamento associado ao êxito, as médias serão muito baixas, porque representam algo que com pouca freqüência se percebe na vida da população pesquisada.

No que se refere à variável sexo, se observam quatro valores de $\mathrm{F}$ significativos. No fator competitividade (F $(1,559)=15,69, \quad p<0,000)$, os homens apresentam as médias mais altas $(\mathrm{M}=3,56)$ do que as mulheres $(\mathrm{M}=3,20)$. No fator dominância ( $\mathrm{F}$ (1, $602)=4,38, p<0,037)$, as mulheres apresentam médias maiores $(5,80)$ em comparação com os homens $(5,66)$. No trabalho $(\mathrm{F}(1,602)=4,30, p<0,039)$, os homens apresentam médias relativamente mais altas $(2,43)$ que as mulheres $(2,25)$. Estes resultados fazem supor que, numa interpretação triangular, os homens podem ser colocados no pólo positivo, se se pretende obter as médias mais elevadas de freqüência. Com relação à insegurança ante a execução de tarefas $(F(1,583)=$ $9,26, p<0,002)$, as mulheres $(3,85)$ demonstram ser mais inseguras que os homens $(3,80)$.

Tabela 3 - Médias de homens e mulheres para orientação e evitação ao êxito

\begin{tabular}{lcccc}
\multicolumn{1}{c}{ Dimensão } & \multicolumn{2}{c}{ Médias } & F & P \\
\hline Competitividade & Mulheres & Homens & 15,69 & 0,000 \\
Dominância & 3,20 & 3,56 & 4,38 & 0,037 \\
Trabalho & 5,80 & 5,66 & 4,30 & 0,039 \\
Insegurança ante a execução & 2,25 & 2,43 & 9,26 & 0,002 \\
Preocupação ante a avaliação social & 4,05 & 3,72 & 0,19 & 0,662 \\
\hline
\end{tabular}

mulheres $(\mathrm{n}=302)$; homens $(\mathrm{n}=301)$

${ }^{*} p<0,000,0,05$

Tabela 4 - Médias para orientação e evitação ao êxito por grupo de idade

\begin{tabular}{|c|c|c|c|c|c|}
\hline \multirow{2}{*}{ Dimensão } & \multicolumn{3}{|c|}{ Médias } & \multirow{2}{*}{$\mathrm{F}$} & \multirow{2}{*}{$\mathrm{P}$} \\
\hline & Grupo 1 & Grupo 2 & Grupo 3 & & \\
\hline Competitividade & 3,60 & 3,12 & 3,30 & 9,32 & 0,000 \\
\hline Dominância & 5,65 & 5,79 & 5,78 & 1,81 & 0,164 \\
\hline Trabalho & 2,53 & 2,56 & 2,15 & 8,02 & 0,000 \\
\hline Insegurança ante a execução & 4,16 & 3,88 & 3,52 & 13,21 & 0,000 \\
\hline Preocupação ante a avaliação social & 4,05 & 3,74 & 3,59 & 6,60 & 0,001 \\
\hline
\end{tabular}

Grupo 1) 14-22 (240), Grupo 2) 23-35 (178), Grupo 3) >36 (141); $p<0,000,0,05$ 
Quanto ao grupo de idade, encontraram-se quatro diferenças estatisticamente significativas (efeitos principais): em competitividade ( F $(2,558)=9,32$, $p<0,001)$; no trabalho (F $(2,601)=8,02, p<0,001)$; na insegurança ante a execução de tarefas (F (2, $582)=13,21, \quad p<0,001)$; e na preocupação ante a avaliação social $(\mathrm{F}(2,545)=6,60, p<0,001)$, as quais se devem ao contraste entre o grupo de adolescentes e o grupo de adultos, em ambas escalas. Isso implica que os adolescentes percebem-se com um alto nível de competitividade, trabalho e evitação, quando comparados a outros grupos de idade. Não obstante, na população total prevalece a preocupação pela avaliação, com uma percepção alta de competitividade e muito baixa de trabalho.

Por série cursada, as diferenças encontradas são em competitividade (F $(2,552)=7,68, \quad p<0,001)$ e insegurança ante a execução de tarefas $(\mathrm{F}(2,574)=7,39$, $p<0,001)$. O terceiro grupo estabelece a diferença com média menor em competitividade $(3,67)$ do que na subescala de evitação ao êxito $(3,78)$. Com relação a ter parceira(o), identificaram-se diferenças significativas no total das dimensões de orientação ao êxito e evitação ao fracasso. O grupo sem parceira(o) apresentou as médias mais baixas em evitação ao êxito, competitividade e trabalho e uma percepção menor de medo à avaliação, o que pode ser interpretado como uma percepção de menor competência nos outros, no tocante ao trabalho, e uma maior tolerância ao fracasso. É pouco provável que os resultados se contaminem pela possibilidade dos sujeitos sem parceira(o) representarem a população com menos de 25 anos, visto que eles não obtêm valores semelhantes aos do grupo de jovens. Em relação à população total, pode-se observar que os valores da percepção em evitação ao êxito são maiores do que os de competitividade e os de trabalho e se encontram em um nível de percepção muito baixa.

Tabela 5 - Média para orientação e evitação ao êxito por escolaridade

\begin{tabular}{lccccc}
\hline \multicolumn{1}{c}{ Dimensão } & Média 1 & Média 2 & Média 3 & F & $p$ \\
\hline Competitividade & 3,42 & 3,59 & 3,18 & 7,68 & 0,001 \\
Dominância & 5,75 & 5,72 & 5,73 & 0,06 & 0,936 \\
Trabalho & 2,38 & 2,36 & 2,29 & 0,41 & 0,660 \\
Insegurança ante a execução & 4,17 & 4,02 & 3,67 & 7,39 & 0,001 \\
Preocupação ante a avaliação social & 3,82 & 3,88 & 3,78 & 0,32 & 0,724 \\
\hline
\end{tabular}

1. Segunda fase do ensino fundamental $(\mathrm{n}=101) ; 2$. Ensino médio $(\mathrm{n}=202) ; 3$. Cursinho $(\mathrm{n}=250) ;{ }^{*} p<0,000$, 0,05

Tabela 6 - Médias para orientação e evitação ao êxito para pessoas com e sem parceira(o)

\begin{tabular}{lcccc}
\hline \multicolumn{1}{c}{ Dimensão } & Média com parceira(o) & Média sem parceira(o) & F & $p$ \\
\hline Competitividade & 3,46 & 3,23 & 5,37 & 0,021 \\
Dominância & 5,68 & 5,84 & 4,40 & 0,036 \\
Trabalho & 2,43 & 2,16 & 8,45 & 0,004 \\
Insegurança ante a execução & 4,04 & 3,56 & 17,84 & 0,000 \\
Preocupação ante a avaliação social & 3,95 & 3,57 & 10,6 & 0,002 \\
\hline
\end{tabular}

Com parceira $(\mathrm{n}=400)$; sem parceira $(\mathrm{n}=198)$

$*_{p}<0,000,0,05$ 


\section{Discussão e conclusões}

Como se pode apreciar nos resultados, as definições conceituais de orientação e evitação ao êxito são compatíveis com as de Spence e Helmreich (1978). Ademais, outros pesquisadores como Díaz, Andrade e La Rosa (1989) e Espinosa e Reyes-Lagunes (1991) encontram resultados semelhantes no México. A confiabilidade e a estrutura fatorial das escalas foram muito semelhantes às encontradas por Laborín e Vera (2000), em uma amostra mexicana, mais especificamente do estado de Sonora. No entanto, na população paraibana, a porcentagem de variância explicada em orientação ao êxito foi mais alta. Tais resultados ratificam que a medição de qualquer construto deve ser específica para cada região cultural (Bontempo, Lobel \& Triandis, 1990; Poortinga, 1989; Triandis, 1994; Vera-Noriega \& Laborín-Alvarez, 2001). Por outro lado, fazem supor que, para a população paraibana, os fatores de orientação e evitação ao êxito se movem de maneira simétrica, por meio de uma dinâmica na qual a competitividade, o domínio e a evitação ao êxito, com suas duas subescalas, conformam, cada um deles, o vértice de um triângulo. Os dados demonstram um processo de intercâmbio, no qual as pessoas com uma boa percepção de competência apresentam médias pouco menores em evitação e domínio, enquanto aquelas com médias altas em evitação ao êxito apresentam médias baixas em percepção de competitividade e domínio. Este tripé de determinação da orientação ao êxito resulta de uma escassa cultura de avaliação e de uma alta predominância da competência entre os pares, em face de um cenário com problemas de desemprego.

Quanto às diferenças por sexo, verificou-se que os homens se orientam mais para a competitividade e para o trabalho. Isso coincide com os estudos de Spence e Helmreich (1978), Díaz, Andrade e La Rosa (1989), Andrade e Reyes-Lagunes (1996), onde foram encontradas diferenças para essas mesmas dimensões, bem como para o domínio. Essas diferenças podem ser aplicadas segundo algumas premissas sócio-históricoculturais (por exemplo: o homem tem que ser provedor e a mulher uma boa mãe) e relacionadas com as práticas de educação dos filhos, que põem ênfase nas relações interpessoais e nas manifestações de afeto (Andrade \& Reyes-Lagunes, 1996). Coerente com a Teoria da Masculinidade-Feminilidade depreende-se que nos homens existe um desejo de lograr reconhecimento social e êxitos econômicos. Quanto às mulheres, percebe-se que, para elas, o alcançar metas não se relaciona com o reconhecimento do grupo (Ibarra, Laborín \& Vera, 2002).
Em relação às dimensões de insegurança ante a execução de tarefas e preocupação ante a avaliação social, os resultados coincidem, nas duas primeiras dimensões, com os encontrados por Laborín e Vera (2000). Desse modo, constataram-se diferenças para insegurança ante a execução de tarefas e dependência de avaliação social, as mulheres apresentando médias maiores para ambas as dimensões. Os resultados auferidos reafirmam a hipótese de que cada vez mais as mulheres estão interessadas em fortalecer características instrumentais que se traduzem em possibilidades de se incorporarem aos mecanismos de produção e integração social (Ibarra, Laborín \& Vera, 2002). Também levam a pensar que existe uma orientação das mulheres em desfrutar a vida laboral, observando critérios de satisfação em aspectos como relações com as companheiras e com os chefes imediatos, prestação de contas com os superiores, entre outros (Espinosa \& Reyes-Lagunes, 1991; Laborín \& Vera, 2000).

Com referência às diferenças por grupo de idade, observa-se que os grupos com mais de trinta anos se encontram atualmente num processo de socialização e questionamento social e familiar de sua forma de ser e possuem altos níveis na dimensão de domínio. Uma explicação possível é pensar que seja em virtude de possuírem um nível de maturação emocional, terem alcançado metas na dimensão afetiva com relação a parceiros e talvez possuírem uma estabilidade econômica que esses grupos não compitam de maneira clara e aberta com os outros. Também são pessoas que não estão acomodadas e continuam buscando situações ou tarefas que envolvam perfeição (Horrocks, 1984, citado por Espinosa, Pick de Weiss \& Reyes-Lagunes, 1988). Essas explicações se apóiam no fato de que as pessoas adultas possuem uma internalização de padrões de excelência que vão conformando sua satisfação e, por conseqüência, sua maior experiência (Espinosa \& Reyes-Lagunes, 1991; Espinosa, 1999).

$\mathrm{Na}$ dimensão de evitação ao êxito, os resultados ratificam uma relação de insegurança ante a execução de tarefas, na etapa de transição da adolescência para a fase adulta. Essa etapa é caracterizada por uma incipiente definição da identidade sexual, conflito de papéis e falta de clareza nas metas. Esses aspectos vão se definindo, se afirmando, conforme aumenta a idade, e diminuem em função da ansiedade e da insegurança pessoal experimentada, em ambos os sexos (Espinosa, 1999; Espinosa, Pick de Weiss \& Reyes-Lagunes, 1988; Laborín \& Vera, 2000).

No que diz respeito à série cursada, os alunos foram divididos em três grupos: o primeiro, dos que possuem da quinta até a sexta série do ensino fundamental; o segundo, dos que cursavam da sétima 
série do ensino fundamental até o primeiro ano do ensino médio; e o terceiro, dos alunos do segundo e terceiro ano do ensino médio e do cursinho prévestibular. Verificaram-se diferenças mínimas entre os grupos, o que coincide com a literatura sobre o assunto, em que se constata que as pessoas com maior escolaridade apresentam menores pontuações em competitividade. Do que foi dito deduz-se que as pessoas (homens e mulheres) da Paraíba, em sua maioria, valorizam o ser competitivo no trabalho e percebem-se em virtude de sua avaliação social e comparação com os outros. Caracterizam-se, também, por procurar realizar as tarefas com empenho e dedicação, com o propósito de serem melhores, sem serem detalhistas ou especialistas. Entretanto, freqüentemente estão expostos a sensações de insuficiência de habilidades e, sobretudo, dependem da referência do grupo de pertença para padronizar os critérios de meta para qualificar seu desempenho (Bontempo, Lobel \& Triandis, 1990; Dela Coleta, 1990). Isso decorre do fato de habitarem uma região que, nos últimos anos, tem experimentado um crescimento econômico e social, e gerado novas formas de atribuição e enfrentamento para novos estilos de orientação, sejam eles de êxitos ou de fracassos (Santos, 1990; Cavalcanti, 1993; De Almeida, 1994; Ribeiro, 1998).

Quanto ao fato de terem ou não parceiros, pode-se perceber que as diferenças na maioria das dimensões refletem que tanto os homens como as mulheres, ao contar com uma parceira(o), se mostraram menos tímidos ante os demais. Esta situação se deve, provavelmente, a um maior sentido de segurança pessoal para a orientação em busca da obtenção de êxitos, o que permite a recreação e o tempo livre como um estilo de satisfação na relação (Kimble, Hirt, Díaz-Loving, Hosch, Lucker \& Zárate, 2002).

A esse respeito, os resultados de Vera e colaboradores (2002) indicam que, para os paraibanos, o trabalho ou fator ocupacional não é algo que os caracteriza ou distingue. Isto é, verificou-se uma atribuição do trabalho mais como uma forma de interação social do que como uma estratégia de orientação ao êxito.

Os resultados obtidos, em seu conjunto, permitem concluir que a orientação e a evitação ao êxito para esse grupo se encontram conformadas por cinco fatores: competitividade, domínio, trabalho, insegurança ante a execução de tarefas e preocupação com relação à avaliação social.

Os resultados indicam que os homens se apresentam como muito mais competitivos do que as mulheres. Estas, por sua vez, mostram maior insegurança ante a execução de tarefas do que os homens, dependendo mais da avaliação social por seus êxitos.
No tocante às características principais dos paraibanos, nota-se que constituem uma cultura que tem uma identidade e uma valoração próprias, em virtude da maneira como conceituam, atribuem e, sobretudo, se dirigem à busca e alcance de suas metas, como resultado de um processo de aculturação que, nos últimos anos, tem caracterizado o país e a região do nordeste do Brasil (Cavalcanti, 1993). Finalmente, quanto, às perspectivas de futuras pesquisas, reputa-se como uma necessidade a realização de investigações transculturais (Poortinga, 1989) e etnopsicológicas com grandes grupos, para avançar o contraste dos resultados em culturas latinoamericanas (Salazar, 1997). Além disso, tais pesquisas permitiriam considerar que, nos construtos de orientação ao êxito e evitação ao êxito, subjaz uma noção de competitividade individual negativa, sedimentada por vários anos, e que, na atualidade, as relações interpessoais e de trabalho se dirigem de forma a fomentar uma cultura de competência e eficácia do grupo (Rodríguez \& Ramírez, 1996). Por outro lado, é importante lograr para o Brasil, de modo semelhante ao que realiza o doutor Rogelio Díaz Guerrero, no México, pesquisar características que possam generalizar-se, com o objetivo de se conformar uma identificação sobre as premissas histórico-socioculturais que definem a cultura do nordeste brasileiro, se se quer compreender melhor a psicologia brasileira (Noriega \& cols., 2002).

\section{Referências}

Acuña, L., Bruner, A. C. \& Avila, R. (1994). Estructura factorial del inventario de roles sexuales de Bem en México. Revista Interamericana de Psicología, 28, 155-168.

Andrade, P. P. \& Díaz-Loving, R. (1985, noviembre). Orientación al logro: conceptualización y medición de maestría, trabajo y competencia. Trabajo presentado en el IV Congreso Mexicano de Psicología. D. F. México.

Andrade, P. P. \& Reyes-Lagunes, I. (1996). Locus de control y orientación al logro en hombres y mujeres. Revista de Psicología Social y Personalidad, 12, 75-84.

Anguas, P. A. M. (1997). El significado del bienestar subjetivo, su valoración en México (Dissertação de Mestrado). México, DF: Universidade Nacional Autônoma do México.

Anguas, P. A. M. \& Reyes, L. I. (1998). El significado del bienestar subjetivo: su valoración en México. La Psicología Social en México (v. 7, pp. 7-11). México: AMEPSO.

Atkinson, J. M. \& Raynor, J. O. (1974). Motivation and achievement. Washington, DC: Van Nostrand Reinhold.

Psico-USF, v. 11, n. 2, p. 207-217, jul./ dez. 2006 
Atkinson, J. W. \& Birch, D. (1978). Introduction to motivation. Nueva York: Van Nostrand.

Bejar, N. R. (1983). El mexicano. Aspectos culturales y psicosociales ( $3^{\mathrm{a}}$ ed.). México: UNAM.

Bontempo, R., Lobel, S. \& Triandis, H. (1990). Compilanse and value internalization in Brazil and the U.S. Journal of Cross-Cultural Psychology, 21, 200-213.

Cattell, R. B. (1966). The screeb test for the number of factors. Multivariate Behavior Research, 1, 245-276.

Cattell, R. B. (1978). The scientific use of factor analysis. New York: Plenum.

Cavalcanti, C. (1993). País e região: desigualdades e preconceitos regionais no Brasil. Cadernos de Estudos Sociais, 9, 25-40.

Cofer, C. N. \& Appley, M. H. (1971). Motivación social. Psicología de la motivación. Teoría e investigación. (cap. 15, pp. 747-781). México: Trillas.

Comrey, A. L. (1988). Factor analytic methods of scale development in personality and clinical psychology. Journal of Consulting and Clinical Psychology, 56, 764-761.

De Almeida, J. A. (1994). A Paraíba e sus problemas. 4ª ed. Brasilia.

Dela Coleta, J. A. (1990). Principales desarrollos y aplicaciones de la teoría de la atribución de causalidad en el Brasil. Revista de Psicología Social y Personalidad, 6, 5773.

De Sousa, E., Koller, S., Hutz, C. \& Forster, L. (1995). Preventing depression among Brazilian street children. Revista Interamericana de Psicología, 29, 261-265.

Díaz, L. R., Andrade, P. P. \& La Rosa, L. (1989). Orientación al logro: Desarrollo de una escala multidimencional (EOL) y su relación con aspectos sociales y de personalidad. Revista Mexicana de Psicología, 6, 1, 21-26.

Díaz-Guerrero, R. (1982) Psicología del mexicano. México: Trillas.

Díaz-Guerrero, R. \& Szalay, L. B. (1993). El mundo subjetivo de mexicanos y norteamericanos. México: Trillas.

Espinosa, F. R. (1999). La personalidad del adolescente y del joven adulto en el ecosistema tradicional: ciudad de Puebla (Tese de Doutorado). México, DF: Universidad Nacional Autónoma de México.

Espinosa, F. R. \& Reyes-Lagunes, I. (1991). La evitación al éxito: validación y calificación del E. E. E. Revista de Psicología Socialy Personalidad, 7, 72-90.

Espinosa, F. R., Pick de Weiss, S. \& Reyes-Lagunes, I. (1988). Temor al éxito: validación del instrumento de medición E. T. E. La Psicología Social en México (v. 2, pp. 46-51). AMEPSO-Trillas.

Floyd, F. J. \& Widaman, K. F. (1995). Factor analysis in the development and refinement of clinical assessment instruments. Psychological Assessment, 7, 286-299.

Girardi, C. \& Díaz-Loving, R. (1990). Escala de atribución de control para adolescentes mexicanos. Revista Sonorense de Psicología, 4, 40-59.

González, A. N. I., López, F. \& Valdés, M. J. L. (1996). Autoconcepto y autoestima en madres e hijos de diferentes escuelas de la Cd. de Toluca. La Psicología Social en México (v. 6, pp. 85-91). México: AMEPSO/Trillas.

Gorsuch, R. (1983). Factor analysis (2da. ed). Hillsdale, New Jersey: Erlbaum.

Gouveia, V. V. \& Clemente, D. M. (1998). La medida del individualismo y del colectivismo. La investigación en el campo de la psicología cultural. Universidade de la Coruña. España.

Hampson, S. E. (1986). La construcción de la personalidad. España: Paidós.

Hayashi, C. T. \& Weiss, M. R. (1994). A Cross-Cultural Analysis of Achievement Motivation in Anglo-American Japanese Marathon Runners. Journal of Sport Psychology, 25, 187-202.

Hermans, H. J. M. (1970). A questionnaire measure of achievement motivation. Journal of Applied Psychology, 54, 353-363.

Herrenkohl, R. C. (1972). Factor analytic and criterion study of achievement motivation. Journal of Educational Psychology, 63, 314-326.

Horner, M. S. (1969). Sex differences in achievement motivation and performance in competitive and noncompetitive situations. Dissertation Abstracts International, 30, 4078 (University Microfilms no 69-12, 15).

Ibarra, S. P., Laborín, A. J. F. \& Vera, N. J. A. (2002). Rasgos de masculinidad-femineidad en población que habita el desierto del noroeste de México. Avances en Psicología Clínica Latinoamericana, 20, 45-56.

Kaiser, H. F., Hunka, S. \& Bianchinf, J. C. (1969). Relation factor between studies based upon different individuals. Em H. J. Eysenck \& S. B. G. Eysenck (Eds.). Personality structure and measurement. Routledge and Kegan Paul.

Kimble, C., Hirt, E., Díaz-Loving, R., Hosch, H., Lucker, G. W. \& Zárate, M. (2002). Atracción interpersonal: amigos y amantes. Psicología social de las Américas (cap. 11, pp. 291-334). México: Pearson Educación. 
Laborín, A. J. F. \& Vera, N. J. A. (2000). Orientación al logro y evitación al éxito en población que habita la región noroeste del desierto de México. Revista Suma Psicológica, 7, 211-230.

La Rosa, J. (1986). Escalas de locus de control y auto concepto: construcción y validación (Tese de Doutorado). México, DF: Universidad Nacional Autónoma de México.

Mankeliunas, M. V. (1987). Psicología de la motivación. México: Trillas.

McClelland, D. C. (1985). Human motivation. New York: Scott Foresman.

McClelland, D. C., Atkinson, J. M., Clark, R. A. \& Lowell, E. L. (1953). The achievement motive. New York: AppletonCentury Crofts.

Mehrabian, A. (1969). Male and female scales of tedency to achieve. Educatioanal and Psychological Measurement, 28, 493502.

Michel, W. (1977). Personalidad y evaluación. México: Trillas.

Noriega, J. A. V., Albuquerque, F. J. B., Laborín, J. F., Silva, A. R. M. \& Avila, M. A. T. (2002). Autoconceito em uma população do nordeste brasileiro. Psico, Porto Alegre, 33(1), 37-52.

Nunnally, J. C. \& Bernstein, I. J. (1995). Teoría psicométrica. ( $3^{\mathrm{a}}$ ed.). México: McGraw-Hill.

Poortinga, I. (1989). Equivalence of cross-cultural data: An overview of basic issues. Holanda: Elsevier Sience.

Raynor, J. O. (1970). Relationships between achievementrelated motives, future orientation, and academic performance. Journal of Personality and Social Psychology, 15, 28-33.

Reeve, J. (1994). Motivación y emoción. España: McGraw Hill.
Reyes-Lagunes, I. (1993). Redes semánticas naturales, su conceptualización y su utilización en al construcción de instrumentos. Revista de Psicología Social y Personalidad, 9, 81-97.

Reyes-Lagunes, I. (1996) Género y control: conceptualización y medición etnopsicológica. Proyecto de investigación no publicado, aprobado y aceptado por CONACYT.

Ribeiro, D. (1998). O povo brasileiro. A formação e o sentido do Brasil. São Paulo: Companhia das Letras.

Rodríguez, E. M. \& Ramírez, B. P. (1996). Psicología del mexicano en el trabajo. México: McGraw Hill.

Salazar, J. M. (1997). La investigación transcultural en 30 años de la Revista Interamericana de Psicología. Revista Interamericana de Psicologia, 31, 169-184.

Santos, M. F. S. (1990). Identidade e aposentadoria. São Paulo: EPU.

Shaw, M. E. \& Constanzo, P. R. (1982). Theories of social psychology ( $2^{\mathrm{a}}$ ed.). New York: McGraw-Hill.

Spence, J. T. \& Helmreich, R. L. (1978). Masculinity and femininity; their psychological dimensions, correlates and antecedents. Austin: The University of Texas Press.

Triandis, H. C. (1994). Cultura. El nuevo énfasis en psicología. Revista de Psicología Social y Personalidad, 10, 1 20.

Vera-Noriega, J. A., Laborín-Alvarez, J. F., DomínguezIbáñez, S. E., Peña-Ramos, M. O. Aplicación del horario de verano en el estado de Sonora, Mexico: una visión retrospectiva. Ethos Ciencia y Cultura, 2(2), 15-24, 2001.

Recebido em fevereiro de 2006 Aprovado em setembro de 2006

Sobre os autores:

Jesús Francisco Laborín Álvarez é mestre em Psicologia Social pela UNAM, Centro de Investigación en Alimentación y Desarrollo, A. C.

José Angel Vera Noriega é doutor em Psicologia Social pela UNAM, Centro de Investigación en Alimentación y Desarrollo, A. C.

Francisco José Batista de Albuquerque é doutor em Psicologia Social pela Univ. Complutense de Madrid e professor do Programa de Pós-Graduação da Universidade Federal da Paraíba.

Carlos Eduardo Pimentel é mestre em Psicologia Social pela Universidade Federal da Paraíba.

Alessandra Patrícia de Araújo Dantas é psicóloga pela Universidade Federal da Paraíba. 
